\title{
Radiographic evaluation of calcaneal fractures: to measure or not to measure
}

\author{
T. Schepers • A. Z. Ginai • P. G. H. Mulder • P. Patka
}

Received: 22 October 2006 /Revised: 6 January 2007 / Accepted: 5 March 2007 / Published online: 7 June 2007

(C) ISS 2007

\begin{abstract}
Objective The aim of this study was to correlate the functional outcome after treatment for displaced intraarticular calcaneal fracture with plain radiography.

Design The design was a prognostic study of a retrospective cohort with concurrent follow-up.

Patients A total of 33 patients with a unilateral calcaneal fracture and a minimum follow-up of 13 months participated. Patients filled in three disease-specific questionnaires, graded their satisfaction and the indication for an arthrodesis was noted. Standardised radiographs were made of the previously injured side and the normal (control) side. Different angles and distances were measured on these radiographs and compared with values described in the literature. The differences in values in angles and distances between the injured and uninjured (control) foot were correlated with the outcome of the questionnaires, and the indication for an arthrodesis.

Results None of the angles correlated with the diseasespecific outcome scores. Of the angles only the tibiotalar
\end{abstract}

T. Schepers $(\bowtie) \cdot$ P. Patka

Department of General Surgery-Traumatology, Erasmus MC, University Medical Centre Rotterdam,

Room H-974, P.O. Box 2040,

3000 CA Rotterdam, The Netherlands

e-mail: t.schepers@erasmusmc.nl

\section{A. Z. Ginai}

Department of Radiology, Erasmus MC,

University Medical Centre Rotterdam,

Rotterdam, The Netherlands

P. G. H. Mulder

Department of Epidemiology and Biostatistics,

Erasmus University Rotterdam,

Rotterdam, The Netherlands angle correlated with the VAS $(r=0.35, p=0.045)$ and only the absolute foot height correlated with the indication for an arthrodesis (odds $=0.70, \mathrm{CI}=0.50-0.99$ ).

Conclusion In this study the radiographic evaluation correlated poorly with the final outcome. Measurements on plain radiographs seem not to be useful in determining outcome after intra-articular calcaneal fractures.

Keywords Calcaneus · Fracture · Outcome assessment . Radiology

\section{Introduction}

The evaluation of calcaneal fractures and determination of the effect of treatment traditionally relies on three pillars, consisting of standardised questionnaires, physical examination and the use of radiographs in various projections. The standard lateral and axial views and the axial according to Harris (posterior oblique image) are well known. Less well known are the oblique views by Brodén [1], Isherwood [2] and Anthonsen [3]. These have proved useful in visualising the extent of the fracture lines in the posterior facet after trauma, but almost all have been replaced by computed tomography (CT) in the last two decades [4]. After the implementation of $\mathrm{CT}$ scanning the usefulness of the standard radiographic projections was questioned, for example the need for an axial view [5]. Besides the different plain radiographic projections, various angles and distances were determined in the lateral and axial view. The value of radiography at follow-up has been a point of discussion for some time. As early as 1955 Maxfield and McDermott [6] concluded that the anatomy as seen radiographically did not correlate well with functional results and the point of view that radiography is of limited value in the evaluation of 
outcome is shared by several authors [7-9]. In contrast, the plain radiograph is more readily available and reduces the risks of radiation significantly. The present study was conducted to investigate the usefulness of plain radiography in determining the outcome of treatment compared with different disease-specific outcome scores in the follow-up of patients with an intra-articular calcaneal fracture.

\section{Material and methods}

Patients with a unilateral intra-articular calcaneal fracture treated between 1998 and 2004 were informed about the study, following approval of the Internal Reviewing Board (IRB). Excluded prior to the study were patients who had deceased $(n=2)$, emigrated $(n=4)$, no known address $(n=5)$, a bilateral fracture $(n=9)$ or who had an arthrodesis performed $(n=5)$. All patients were treated using the percutaneous distraction technique by Forgon [10], which was introduced in our institute in 1998, and had a minimum follow-up of at least 13 months.

\section{Outcome measurement}

At follow-up patients were invited to the outpatient clinic and were asked to complete the Maryland Foot Score (MFS), the Creighton-Nebraska score $(\mathrm{CN})$ and the American Orthopedic Foot and Ankle Society Hindfoot score (AOFAS) questionnaires [11-13]. The MFS, CN and AOFAS scores are disease-specific outcome scores consisting of 9, 7 and 10 individual items respectively and have a range of 0 points minimum and 100 points maximum each. In addition to the three different outcome scores, patient satisfaction was assessed on a single question Visual Analogue Scale (VAS) analysed on a scale of 100 millimetres $(\mathrm{mm})$. Zero millimetres represented the worst possible outcome and $100 \mathrm{~mm}$ was scored if patient satisfaction was excellent. The single question VAS is part of the multiple question VAS as proposed by Hildebrand et al., who found good correlation between the VAS and the disease-specific outcome score by Rowe as well as with the Short Form-36 [14]. The range of motion of both ankles and subtalar joints was measured as part of the different outcome scores.

\section{Radiographic technique}

Plain radiographs were taken of both feet in exactly the same fashion: a weight-bearing lateral view and an axial view. The film focus distance (FFD) was $105 \mathrm{~cm}$ in all cases. All distances from foot to camera and all settings were kept the same. In these radiographs different angles and distances were measured with a hand-held goniometer by two independent observers (TS, AG), and each set of two values was averaged. Any measurement discrepancy of more than $5^{\circ}$ was settled by consensus. The angles were compared with reference values as mentioned in the literature.
Fig. 1 Graphical representation of measurement of different angles and distances (for explanation see Material and methods). a-c Weight-bearing lateral view. $A$ Böhler's angle; $B$ Gissane's angle; $C$ calcaneal inclination angle; $D$ talocalcaneal angle; $E$ tibiotalar angle; $F$ tibiocalcaneal angle; $G$ talarhorizontal angle; $H$ talar declination angle; $I$ length of calcaneus; $J$ calcaneal facet height; $K$ absolute foot height; $L$ facet inclination angle. d Axial view. $M$ width of calcaneus
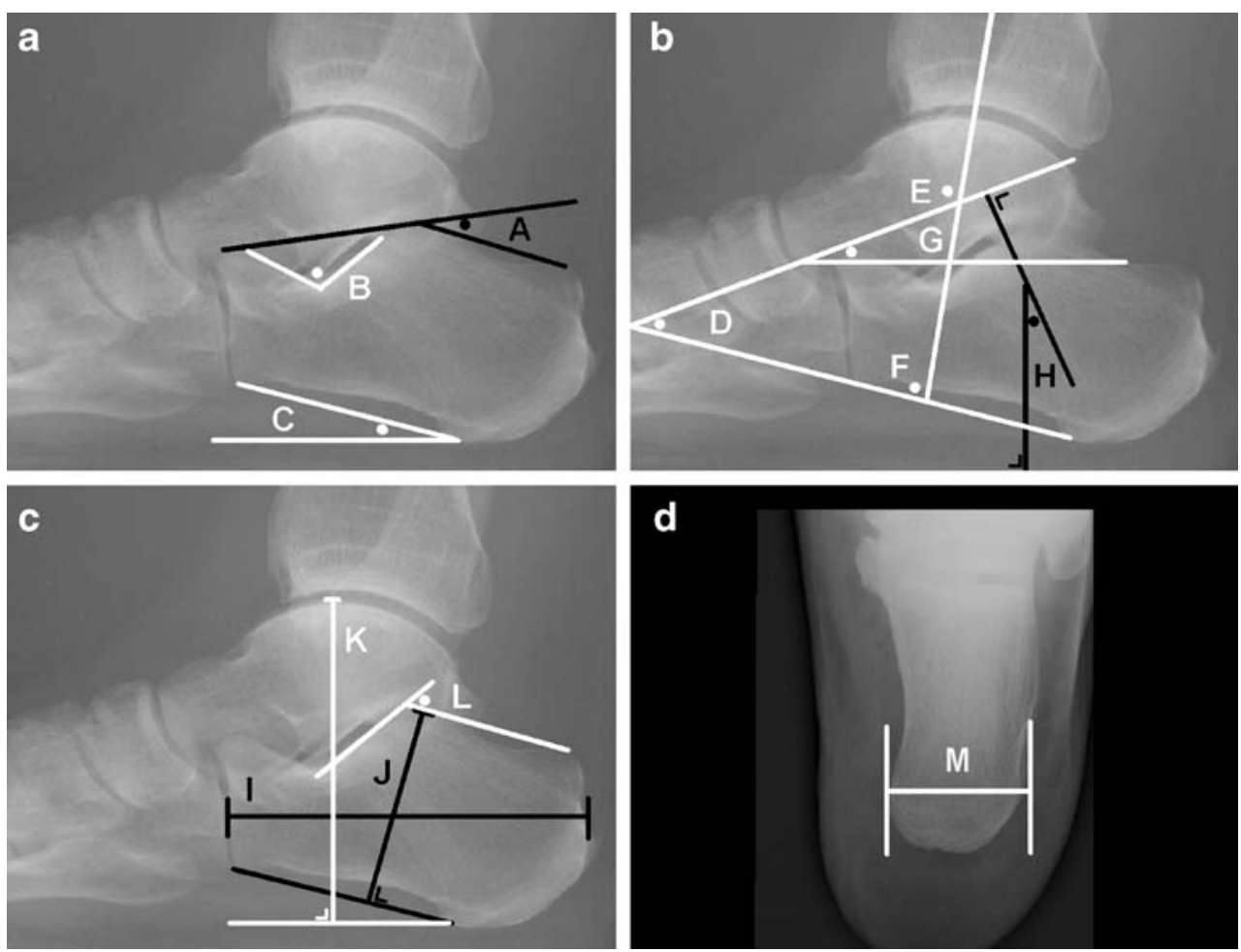
The angles measured were: Böhler's tuber angle, Gissane's crucial angle, the calcaneal inclination angle, the talar declination angle, the tibiotalar, the talocalcaneal and the tibiocalcaneal angle (Fig. 1).

The distances measured were: the calcaneal width, the calcaneal facet height, the absolute foot height and the calcaneal length (Fig. 1). In contrast to the angles above there are no reference values for length, height and width measurements. These have to be compared with the contralateral healthy side.

\section{Radiographic measurements}

All angles and distances measured are shown in Fig. 1.

Böhler's tuber joint angle by (Angle A) is measured using the highest points of the calcaneal tuberosity, the subtalar joint and the anterior process and is taken as a relative measurement of the degree of compression and deformity in calcaneal fractures.

The crucial angle, as described by Gissane (Angle B), is the angle formed by the posterior facet and the line from the calcaneal sulcus to the tip of the anterior process of the calcaneus.

The calcaneal inclination or calcaneal pitch angle (Angle C) is formed by the line connecting the most inferior part of the tuberosity of the calcaneus to the most distal and inferior part of the calcaneus along the calcaneocuboid joint (calcaneal axis) and the plane of support, which is defined by the line connecting the most inferior part of the calcaneal tuberosity with the most inferior part point of the fifth metatarsal head [15-17].

The lateral talocalcaneal angle is formed by the calcaneal axis and the collum tali axis (Angle D). This angle is a measure of the hindfoot alignment. The angle decreases when there is varus angulation of the hindfoot or when the foot is in dorsiflexion. The talocalcaneal angle increases with valgus or plantar flexion [18]. There are two ways of measuring this angle (depending on which line is to be chosen as the calcaneal axis). Some authors use the centre line of the calcaneus as axis $[16,19]$. Others use the line formed by the most inferior part of the calcaneal tuberosity and the most inferior point of the calcaneocuboid joint [15, 17]. The latter is less likely to be affected by inter-observer variability, because of the use of fixed points, and was used in the current study.

The tibiotalar angle (Angle E) on the lateral radiograph is formed by the axis of the tibia and the axis of the talus.

The tibiocalcaneal angle (Angle F) is formed by the axis of the tibia and the axis of the calcaneus. The angle increases with plantar flexion and subsequently decreases with dorsal flexion of the foot [18].

The talar declination angle (Angle $\mathrm{H}$ ) is formed by the intersection of perpendicular lines drawn from the axis of the collum tali, which bisects the head and neck of the talus, and the plane of support. This line is essentially the same as the horizontal angle of the talus (Angle G), as described by Vanderwilde, and quantifies the anterior tibiotalar impingement according to Quill [18].

The posterior facet inclination (Angle L), as described by Sarrafian, is the angle formed by the two intersecting lines drawn along the surface of the posterior facet and along the upper surface of the calcaneal tuberosity.

The length of the calcaneus (Distance I) is measured on the lateral view from the most posterior point of the tuberositas to the calcaneocuboid joint. The height of the posterior facet (Distance $\mathrm{J}$ ), as described by Leung et al., is measured by a line perpendicular on the calcaneal axis to the highest point of the posterior facet [20]. The absolute foot height or talocalcaneal height (Distance $\mathrm{K}$ ) is measured from the plane of support to the upper point of the talus [19]. The width of the calcaneus (Distance $\mathrm{M}$ ) is measured on the axial view, as described by Böhler, or on the Harris-Beath projection [20-22].

\section{Statistical analysis}

Statistical analysis was performed using the Statistical Package for the Social Sciences (SPSS) version 11.0 (SPSS, Chicago, IL, USA). The Spearman rank correlation coefficient was used for the correlation of ordinally scaled data. For the dichotomous outcome variable "indication for an arthrodesis (yes/no response)" the odds ratio, including the 95\% confident interval (CI), was calculated. Within-patient difference between the injured and the uninjured side were tested using the Wilcoxon signed rank test. Correlations were considered statistically significant with a $p$ value of $\leq 0.05$. An independent statistician performed all analyses.

\section{Results}

A total of 33 patients was available at follow-up. The average follow-up was 29 months (range 13-75 months). The average age at trauma was 46 years (range 18-65 years), 76\% were male. The right foot was injured in 16 patients and the left foot in 17 . Four patients $(12 \%)$ had an indication for a secondary arthrodesis because of disabling residual pain during followup. These patients filled in the questionnaires and had the standardised radiographs taken prior to the operation. The mean outcome scores were: AOFAS 85 points, MFS 80 points and $\mathrm{CN} 78$ points out of 100 points each, and the VAS reached 7 out of 10 points.

Radiographic data

Böhler's angle According to Böhler, the angle normally ranges from 25 to $40^{\circ}$ [21]. One study reported an average 
angle of $30 \pm 6^{\circ}$ in 120 patients with a normal radiograph [23]. In this study the average angle measured $16^{\circ}$ on the injured side, compared with an average of $32^{\circ}$ on the uninjured side.

Gissane's angle Gissane's angle varies between 120 and $145^{\circ}$ in the literature [24]. In the present study the mean angle was $113^{\circ}$ on the uninjured side, and $108^{\circ}$ on the injured side.

Facet inclination In the literature, the posterior facet inclination angle measures an average of $65^{\circ}$, with a range of $55-75^{\circ}$ [25]. It measured $54^{\circ}$ on the injured side and 66 on the uninjured side in the study group.

Tibiotalar angle Vanderwilde found a quite constant mean tibiotalar angle of about $110^{\circ}$ on the non-weight-bearing lateral view [18]. Our population showed a normal tibiotalar angle of $105^{\circ}$ versus 103 on the injured side.

Talar declination angle Values vary slightly in the literature between 19 and $25^{\circ}$ [17]. In the present study it measured $16^{\circ}$ on the injured side compared with $20^{\circ}$ on the uninjured side.

Calcaneal inclination angle The angle varied between 20 and $30^{\circ}$, according to Bryant et al. [17]. In the current study the uninjured side measured $23^{\circ}$ and on the injured side $21^{\circ}$.

Talocalcaneal angle The normal range varies between 35 and $50^{\circ}$ and between 25 and $45^{\circ}$ in the literature $[15,26]$. However, an even larger range, from 15 to $60^{\circ}$, is mentioned [18]. In our population of unilateral fractures the angle on the uninjured side measured $43^{\circ}$ versus $37^{\circ}$ on the injured side.

Tibiocalcaneal angle It ranged from 60 to $75^{\circ}$ on the nonweight-bearing lateral X-ray in the literature [18]. There was a slight increase in the angle after trauma in this series from $62^{\circ}$ on the uninjured side to $65^{\circ}$ on the injured side.

Width Width increased from $40 \mathrm{~mm}$ on the uninjured side to $46 \mathrm{~mm}$ on the injured side.

Facet height On the uninjured normal side it measured $50 \mathrm{~mm}$, whereas it was $47 \mathrm{~mm}$ on the injured side.

Absolute foot height The normal value was $81 \mathrm{~mm}$ and on the injured side it was $77 \mathrm{~mm}$.

Length The length measured $82 \mathrm{~mm}$ on both sides.

All differences in angles between the injured side at followup and the uninjured side were significant, except for that of the tibiotalar angle (Table 1). Of the distances measured all differences between the injured and uninjured side were statistically significant, except for the length of the calcaneus (Table 2). When correlating the angle and distance differences with the outcome scores and the VAS, only the tibiotalar angle correlated significantly with the VAS $(r=0.35, p=0.045)$.

When correlating the angles and distances with the indication for an arthrodesis, only a significant correlation with the decrease in absolute foot height was found (odds= $0.70, \mathrm{CI}=0.50-0.99$ ). The AOFAS, MFS, $\mathrm{CN}$ and VAS were significantly related to the indication for an arthrodesis (odds $=0.91 \quad[\mathrm{CI}=0.83-0.99], 0.93 \quad[\mathrm{CI}=0.87-0.99], 0.93$ $[\mathrm{CI}=0.87-0.99]$, and $0.14[\mathrm{CI}=0.023-0.825]$ respectively).

\section{Discussion}

In this study, only two correlations were found between the measurements on the standardised radiographs and the

Table 1 Differences in calcaneal angles between injured and uninjured feet

\begin{tabular}{|c|c|c|c|c|}
\hline Angle & Reference (degrees) & Uninjured (degrees) & Injured (degrees) & $p$ value \\
\hline Böhler & $25-40$ & $32(25-40)$ & $16(-10-40)$ & $<0.001$ \\
\hline Gissane & $120-145$ & $108(90-125)$ & $113(80-140)$ & 0.023 \\
\hline Facet inclination & $55-75$ & $66(51-80)$ & $54(15-75)$ & $<0.001$ \\
\hline Tibiotalar & 110 & $105(94-128)$ & $103(92-110)$ & 0.101 \\
\hline Talar declination & $19-25$ & $20(15-28)$ & $16(10-26)$ & $<0.001$ \\
\hline Calcaneal inclination & $20-30$ & $23(12-33)$ & $21(13-29)$ & 0.028 \\
\hline Talocalcaneal & $25-45$ & $43(32-58)$ & $37(23-57)$ & $<0.001$ \\
\hline Tibiocalcaneal & $60-75$ & $62(45-81)$ & $65(35-80)$ & 0.011 \\
\hline
\end{tabular}

Normal values as mentioned in the literature on various plain radiographic angles, compared with the mean normal values of uninjured feet and mean follow-up values of injured feet in 33 patients in this study (range). A $p$ value $<0.05$ indicates a significant difference in angles between the injured and uninjured feet using the Wilcoxon signed rank test 
Table 2 Differences in calcaneal distances between injured and uninjured feet

\begin{tabular}{lccc}
\hline Size & Uninjured (mm) & Injured (mm) & $p$ value \\
\hline Width & $40(35-46)$ & $46(37-56)$ & $<0.001$ \\
Facet height & $50(43-56)$ & $47(38-58)$ & 0.001 \\
Absolute foot height & $81(67-92)$ & $77(65-90)$ & $<0.001$ \\
Length & $82(71-93)$ & $82(71-92)$ & 0.701 \\
\hline
\end{tabular}

Normal values of various distances as measured on the lateral and axial plain radiographs and mean values of injured feet as measured in 33 patients (range) with a unilateral calcaneal fracture. A $p$ value $<0.05$ indicates a significant difference in distance between the injured and uninjured feet using the Wilcoxon signed rank test.

outcome scores. The tibiotalar angles correlated significantly with the VAS and the absolute foot height correlated significantly with the indication for a secondary arthrodesis. All other angles and distances showed no significant correlation with the outcome. The outcome scores, which consist of clinical items and measurements at physical examination, did correlate significantly with the indication for an arthrodesis. The correlation coefficient between the tibiotalar angle and the VAS was 0.35 , indicating a weak correlation, which possibly occurred by chance because of multiple testing.

Weight-bearing radiographs provide a reflection of the structural and functional aspects of the foot, and are therefore frequently used in the pre- and postoperative assessment of conditions of the foot [17]. Bryant showed in his study that repeated measurements on weight-bearing foot radiographs taken on two different occasions have a strong correlation, indicating that weight-bearing foot radiographs can be reliably reproduced [27]. Another study showed that measurements are not significantly affected by slightly different central ray centring points [23]. Three precautions have to be taken into account when making these radiographs: the normal side must be used for comparison; true lateral projections must be used; and the $\mathrm{X}$-ray cassette must be placed on the same side of the foot every time [28]. Several other authors concur that comparison with radiographs of the uninjured side is helpful, especially to determine the normal value for the different angles, like that of Böhler [29-32].

Böhler's angle and Gissane's angle, as measured on the lateral radiograph of the calcaneus, are the most frequently assessed angles in the evaluation of calcaneal fractures. They can give some idea of the severity of the injury, but cannot clearly delineate the location and extent of the lesion [11]. Many authors use different reference values, as mentioned above. Several studies found correlations with the outcome and measurements of Böhler's angle, usually with extremes of Böhler's angle or when division of Böhler's angle into three groups was applied ("less than zero degrees", "zero to $15^{\circ}$ " and " $16^{\circ}$ or higher") [33-36]. Frequently, there is no correlation between the angle and functional results of treatment $[7,11,37,38]$. Correlations between the crucial angle, as described by Gissane, and the final outcome were never found [11, 20, 38].

The angles and distances measured in the current study give an adequate comparison of bone anatomy between the two feet, but do not take into account the condition of the posterior facet. Earlier studies graded osteoarthritis and the postoperative step-off in the posterior talocalcaneal facet, but their correlation with outcome is unclear $[20,36]$. The grading of osteoarthritis and postoperative step-off is difficult and most likely prone to interobserver variability. Second, Letournel stated that plain radiographs are not successful in the assessment of the posterior facet at followup [8]. This is in concordance with earlier findings. In their study of freshly amputated lower extremities, in which the bony landmarks were marked with lead wires, Shereff and Johnson showed that only the central third of the posterior subtalar joint could be visualised on the lateral projection and the axial view showed only the anterior third [39]. To overcome this problem various radiographic angles were defined; each showing a different part of the articulating surfaces of the calcaneus $[1-3,22]$. Still, the tarsal bones superimpose and the articular surfaces can be extremely difficult to access [40]. Also, the problem of reproducing the highly specialised projections makes evaluating the calcaneus, especially after a fracture, difficult and time-consuming [2].

In 1975, Soeur and Remy stated that the use of CT scanning had not been proven useful and was not recommended [30]. CT became increasingly available in the early 1980 s and was used to visualise hindfoot pathology, especially calcaneal fractures. This brought about important change in the understanding of complex intraarticular calcaneal fractures [4]. Nowadays, fast multislice CT scanning with multiplanar reconstructions, is considered the preoperative imaging modality of choice. Only a few retrospective studies show a correlation between the condition of the posterior facet, as seen on $\mathrm{CT}$, before and after surgical treatment and final outcome [13, 41]. However, it remains unclear whether or not it is also a more appropriate tool for assessment at follow-up [42].

\section{Conclusion}

Of the traditional three pillars on which the evaluation of outcome after treatment of intra-articular calcaneal fractures rests, outcome scores, physical examination and plain radiography, the latter appears to give very little information concerning the outcome of treatment. It is useful in determining fracture healing, alignment and the 
restoration of anatomy as aimed for by operation. For the actual measurement of outcome physical and clinical evaluations remain the most important tools. The role of $\mathrm{CT}$ assessment at follow-up has to be further investigated.

\section{References}

1. Brodén B. Roentgen examination of the subtaloid joint in fractures of the calcaneus. Acta Radiol 1949;31: 85-91.

2. Isherwood I. A radiological approach to the subtalar joint. J Bone Joint Surg 1961;43-B 3: 566-574.

3. Anthonsen W. An oblique projection for roentgen examination of the talo-calcanean joint, particularly regarding intra-articular fracture of the calcaneus. Acta Radiol 1943;24: 310-606.

4. Guyer BH, Levinsohn EM, Fredrickson BE, Bailey GL, Formikell M. Computed tomography of calcaneal fractures: anatomy, pathology, dosimetry, and clinical relevance. AJR Am J Roentgenol 1985;145(5): 911-919.

5. Utukuri MM, Knowles D, Smith KL, Barrie JL, Gavan D. The value of the axial view in assessing calcaneal fractures. Injury 2000;31(5): 325-326.

6. Maxfield JE, McDermott F. Experiences with the Palmer open reduction of fractures of the calcaneus. J Bone Joint Surg Am 1955;37-A(1): 99-106.

7. Pozo JL, Kirwan EO, Jackson AM. The long-term results of conservative management of severely displaced fractures of the calcaneus. J Bone Joint Surg Br 1984;66(3): 386-390.

8. Letournel E. Open treatment of acute calcaneal fractures. Clin Orthop Relat Res 1993;290: 60-67.

9. Kennedy JG, Jan WM, McGuinness AJ, et al. An outcomes assessment of intra-articular calcaneal fractures, using patient and physician's assessment profiles. Injury 2003;34(12): 932-936.

10. Forgon M. Closed reduction and percutaneous osteosynthesis: technique and results in 265 calcaneal fractures. In: Tscherne H, Schatzker J, editors. Major fractures of the pilon, the talus, and the calcaneus. Berlin: Springer 1993; pp 207-213.

11. Crosby LA, Fitzgibbons T. Computerized tomography scanning of acute intra-articular fractures of the calcaneus. A new classification system. J Bone Joint Surg Am 1990;72(6): 852-859.

12. Kitaoka HB, Alexander IJ, Adelaar RS, Nunley JA, Myerson MS, Sanders M. Clinical rating systems for the ankle-hindfoot, midfoot, hallux, and lesser toes. Foot Ankle Int 1994;15(7): 349-353.

13. Sanders R, Fortin P, DiPasquale T, Walling A. Operative treatment in 120 displaced intraarticular calcaneal fractures. Results using a prognostic computed tomography scan classification. Clin Orthop Relat Res 1993;290: 87-95.

14. Hildebrand KA, Buckley RE, Mohtadi NG, Faris P. Functional outcome measures after displaced intra-articular calcaneal fractures. J Bone Joint Surg Br 1996;78(1): 119-123.

15. Gentili A, Masih S, Yao L, Seeger LL. Pictorial review: foot axes and angles. Br J Radiol 1996;69(826): 968-974.

16. Buch BD, Myerson MS, Miller SD. Primary subtalar arthrodesis for the treatment of comminuted calcaneal fractures. Foot Ankle Int 1996;17(2): 61-70.

17. Bryant A, Tinley P, Singer K. A comparison of radiographic measurements in normal, hallux valgus, and hallux limitus feet. J Foot Ankle Surg 2000;39(1): 39-43.

18. Vanderwilde R, Staheli LT, Chew DE, Malagon V. Measurements on radiographs of the foot in normal infants and children. $\mathrm{J}$ Bone Joint Surg Am 1988;70(3): 407-415.

19. Rammelt S, Grass R, Zawadski T, Biewener A, Zwipp H. Foot function after subtalar distraction bone-block arthrodesis. A prospective study. J Bone Joint Surg Br 2004;86(5): 659-668.
20. Leung KS, Yuen KM, Chan WS. Operative treatment of displaced intra-articular fractures of the calcaneum. Medium-term results. J Bone Joint Surg Br 1993;75(2): 196-201.

21. Böhler L. Diagnosis, pathology and treatment of fractures of the os calcis. J Bone Joint Surg 1931;13: 75-89.

22. Harris R, Beath T. Etiology of peroneal spastic flat foot. J Bone Joint Surg 1948;30B(4): 624-634.

23. Chen MY, Bohrer SP, Kelley TF. Boehler's angle: a reappraisal. Ann Emerg Med 1991;20(2): 122-124.

24. Essex-Lopresti P. The mechanism, reduction technique, and results in fractures of the os calcis, 1951-52. Clin Orthop Relat Res 1993;290: 3-16.

25. Sarrafian SK. Biomechanics of the subtalar joint complex. Clin Orthop Relat Res 1993;290: 17-26.

26. Romash MM. Reconstructive osteotomy of the calcaneus with subtalar arthrodesis for malunited calcaneal fractures. Clin Orthop Relat Res 1993;290: 157-167.

27. Bryant JA. A comparison of radiographic foot measurements taken in two different positions. J Am Podiatr Med Assoc 2001;91 (5): 234-239.

28. Aaron DA, Howat TW. Intra-articular fractures of the calcaneum. Injury 1976;7(3): 205-211.

29. Hall RL, Shereff MJ. Anatomy of the calcaneus. Clin Orthop Relat Res 1993;290: 27-35.

30. Soeur R, Remy R. Fractures of the calcaneus with displacement of the thalamic portion. J Bone Joint Surg Br 1975;57(4): 413-421.

31. Stephenson JR. Treatment of displaced intra-articular fractures of the calcaneus using medial and lateral approaches, internal fixation, and early motion. J Bone Joint Surg Am 1987;69(1): $115-130$.

32. Lowery RB, Calhoun JH. Fractures of the calcaneus. I. Anatomy, injury mechanism, and classification. Foot Ankle Int 1996;17(4): 230-235.

33. Slatis P, Kiviluoto O, Santavirta S, Laasonen EM. Fractures of the calcaneum. J Trauma 1979;19(12): 939-943.

34. Loucks C, Buckley R. Bohler's angle: correlation with outcome in displaced intra-articular calcaneal fractures. J Orthop Trauma 1999;13(8): 554-558.

35. Buckley R, Tough S, McCormack R, et al. Operative compared with nonoperative treatment of displaced intra-articular calcaneal fractures: a prospective, randomized, controlled multicenter trial. J Bone Joint Surg Am 2002;84-A(10): 1733-1744.

36. Paley D, Hall H. Intra-articular fractures of the calcaneus. A critical analysis of results and prognostic factors. J Bone Joint Surg Am 1993;75(3): 342-354.

37. Kitaoka HB, Schaap EJ, Chao EY, An KN. Displaced intraarticular fractures of the calcaneus treated non-operatively. Clinical results and analysis of motion and ground-reaction and temporal forces. J Bone Joint Surg Am 1994;76(10): 1531-1540.

38. Ebraheim NA, Elgafy H, Sabry FF, Freih M, Abou-Chakra IS. Sinus tarsi approach with trans-articular fixation for displaced intra-articular fractures of the calcaneus. Foot Ankle Int 2000;21 (2): $105-113$.

39. Shereff MJ, Johnson KA. Radiographic anatomy of the hindfoot. Clin Orthop Relat Res 1983;177: 16-22.

40. Smith RW, Staple TW. Computerized tomography (CT) scanning technique for the hindfoot. Clin Orthop Relat Res 1983;177: 34 38.

41. Song KS, Kang CH, Min BW, Sohn GJ. Preoperative and postoperative evaluation of intra-articular fractures of the calcaneus based on computed tomography scanning. J Orthop Trauma 1997;11(6): 435-440.

42. Richards PJ, Bridgman S. Review of the radiology in randomised controlled trials in open reduction and internal fixation (ORIF) of displaced intraarticular calcaneal fractures. Injury 2001;32(8): 633-636. 